\title{
Inclusion of Efficacy Experiences: Providing Intentional Clinical Experiences to Preservice Teachers in Elementary Classrooms
}

\author{
Dr. Garrett Lowder \\ Executive Director \\ Academic Services at the Marshfield R-1 School District \\ Dr. Diana L. Piccolo \\ Associate Professor \\ Missouri State University
}

\begin{abstract}
Recent efforts to improve teacher preparation practices have called universities to place focus on enhancing clinical experiences of preservice teachers. Efforts to meet this call have resulted in little data furthering understanding of enhanced clinical experiences on self-efficacy belief development. In this case study, the researcher analyzed a new elementary preparation program employing an immersive, yearlong clinical experience. The researcher sought to understand if socialization into communities of practice during the experience influenced development of preservice teacher self-efficacy beliefs. The researcher analyzed the level of participant socialization and its influence on efficacy source experiences specifically. Additionally, the researcher analyzed if socialization facet variances across intern responses may have affected socialization.
\end{abstract}

Findings indicated efficacy source experiences are linked to individuals' level of socialization. Efficacy source experiences changed as participant socialization levels changed. Less socialized participants perceived experiences differently and experienced a lack of feedback from mentors.

Key words: "Self-Efficacy”, "Socialization”, "Teacher Preparation”, "Teacher Internship", "Teacher Efficacy"

\section{Problem Statement}

This study sought to identify how processes involved in socialization into a community of practice impacted selfefficacy belief development, leading to a better understanding of best practices in teacher preparation. Effective preparation of teachers has long been a worthy endeavor of universities, as the effectiveness of the classroom teacher is touted to be the Number 1 influence on the achievement of students (NCATE, 2010). It is known that cultivating selfefficacy beliefs within teachers is a necessary and important target for preparation programs, and that opportunities for practice, intentional observation, and effective feedback are critical to its development. However, little to no research exists analyzing the value of socialization processes in a community of practice and its impact on teachers' sense of efficacy.

\section{Theoretical Framework}

Bandura (1997) portrayed self-efficacy as "people's beliefs in their capabilities to produce desired effects by their actions" (p. vii). Self-efficacy deals with one's ability to judge their abilities and capabilities. Bandura devised that inefficacious people who do not believe that they can produce a desired result will likely not, as they will never attempt to do it at all. Conversely, efficacious individuals are prompt to seize opportunity.

Bandura (1997) proposed that self-efficacy is malleable. It can be changed.

Bandura defined four key sources of self-efficacy: enactive mastery experience, vicarious experience, verbal persuasion, and physiological and affective states. These sources refer to an individual's opportunity to see tasks modeled by another, receive feedback from others on tasks, and personally master experiences while operating within a specified physiological and mental state. Each source works in concert with one another to create efficacy within an individual's development of efficacy.

Lave and Wenger (1992) presented legitimate peripheral participation (LPPT) theory as a social learning theory in which individuals learn by means of socialization into a community of practice via active and legitimate participation in the community. In this theory, a critical aspect of the learning process is access to the community of practice. Smith (2009) suggested that communities of practice are "groups of people who share and concern or passion for something they do and learn how to do it better as they interact regularly" (p. 12). 
Smith further suggested three specific elements that must exist for a community of practice to be present: a domain, a community, and a practice. Lave and Wenger (1992) proposed LPPT as a means of newcomers becoming participants and eventually members of a community of practice. In their theory, they proposed that learning does not exist separate from socialization into the community. A learner must become "a full participant, a member, and kind of person" (Lave \& Wenger, 1992, p. 53) within the community of practice. Furthermore, Lave and Wenger argued, "Activities, tasks, functions, and understandings do not exist in isolation" (p. 53).

Lave and Wenger (1992) detailed that for LPPT to be a possibility, newcomers must have full access to the community and be seen as a legitimate participant or member. Participants must be legitimate participants in a manner in which they are immersed to the degree that they can move from peripheral participant to full participant. Lave and Wenger provided that peripheral participants begin with short and simple tasks and progressively take on more responsibility. As participants move toward full participation, the process "involves not just a greater commitment of time, intensified effort, and more and broader responsibilities within the community, and more difficult and risky tasks, but, more significantly, and increasing sense of identity as a master practitioner" (Lave \& Wenger, 1992, p. 111).

\section{Efficacy in the Teaching Profession}

Woolfolk (2007) defined teachers' sense of efficacy as "a teacher's belief that he or she can reach even difficult students to help them learn" (p. 334). Walter (2015) suggested that self-efficacy is an accurate predictor of teaching skills. Data from his study of preservice teachers supported a significantly stronger correlation between self-efficacy and teaching skills than traditionally used cognitive measures of entrance into the teaching field. Furthermore, Woolfolk Hoy (2000) found that teacher preparation program experiences have a direct impact on teacher efficacy beliefs, finding teacher efficacy to be a strong predictor of teaching success.

Bandura's (1977) findings revealed that an individual's efficacy expectations directly impact the intensity and persistence of his/her efforts. "Efficacy expectations determine how much effort people will expend and how long they will persist in the face of obstacles and aversive experiences. The stronger the perceived efficacy, the more active the efforts" (Bandura, 1977, p. 194). Research conducted by Lin (2016) provided similar support for this theory, as computing majors with higher degrees of self-efficacy showed greater degrees of persistence than those who were less efficacious. Furthermore, efficacious teachers demonstrate higher degrees of competence, having more studentcentered lessons, higher levels of student engagement, increased levels of praise, and decreased burnout (Filatov \& Pill, 2015). Woolfolk Hoy's (2000) indication of teachers' sense of efficacy as a key factor in teacher effectiveness resonates with Bandura's (1977) notion of effort and persistence being a byproduct of its existence.

Though findings support that efficacy sources are an important facet for developing efficacy beliefs, it is important to note that application of theory may be accompanied by some ambiguity. Bautista (2011) found that numerous experiences both related and unrelated to efficacy sources could contribute to an increase in efficacy beliefs. Tschannen-Moran and McMaster (2010) found that one group of teachers receiving mere lecture on reading instruction demonstrated a greater increase in efficacy beliefs than groups receiving experiences including multiple sources of efficacy.

Furthermore, data from the same study revealed that application of efficacy sources did not have a significant impact on efficacy beliefs when applied in large group settings, suggesting that experiences should be personalized and individualized. Tuchman and Isaacs (2011) subscribed to this reality as data from their study of formal and informal experiences on preservice teacher efficacy beliefs suggested that quality of experience and not simply its occurrence impact efficacy. In some cases, efficacy source-based experiences even led to a decrease in efficacy beliefs when quality was lacking. Though efficacy sources are generally linked to an increase in efficacy, Al-Awidi and Alghazo (2012) also found that all sources might not be equal.

Methodology

The purpose of this study was to identify whether acting as legitimate participants in a community of practice led to preservice teachers who were more efficacious. Does socialization into a community of practice impact the development of teachers' sense of efficacy? Additionally, what facets of the experience lead to differences in teacher sense of efficacy? This case study attempted to clarify the practices in a teacher preparation journey that affected the efficacy of preservice teachers.

\section{Research Questions}

1. How does socialization into a community of practice impact self-efficacy source experiences?

2. What differences, if any, exist between self-efficacy source experiences of peripheral participants and full participants in a community of practice? 
3. What legitimate peripheral participation theory facets of the clinical experience affected the process of socialization from peripheral participant to full participant?

\section{Participants}

This qualitative case study focused on 10 senior, preservice teachers in the second year of a yearlong, course embedded elementary teacher preparation program and their 10 master teachers acting as the cooperating teachers for the interns. This case study utilized qualitative methods of data collection including semi-structured focus group interviews of interns and master teachers and journaling. The researcher was an assistant principal on one of the campuses during the study and served as a master teacher during the 2015-2016 school year. It was important to the researcher to better understand the impact of the new preparation methods on incoming teachers to the profession. The researcher had hired multiple graduates from the program who demonstrated high rates of success in their first year of teaching. An outside transcription service was used during the analysis of interview recordings to increase accuracy and prevent bias.

The internship program being facilitated by the southwest Missouri university was in its second academic year. Intern participants during the 2016-2017 school year totaled 29. These interns participated in a yearlong clinical experience, which immersed preservice teachers in the public-school setting for the entirety of the school year. Interns participated in 20 days of coursework classified as seminar days by the university. Outside of the 20 seminar days, the interns spent no other days out of the classroom. Interns began in August with their mentor teacher and concluded their clinical experience at the end of the spring semester in May. Interns were located on the campuses of six local school districts surrounding the university campus.

The researcher distributed a selection questionnaire to all 29 university program interns during the Spring semester of their internship experience. The intent of the questionnaire was to identify the degree of socialization each of the interns were currently experiencing based on facets described in Lave and Wenger's (1992) description of legitimate peripheral participation theory. A sample of the questionnaire structure is provided in Table 1 providing how questions were structured and scored.

Each question related to an identified facet of the theory and was asked directly and inversely.

Explanation of Scoring on Participant Selection Questionnaire

\begin{tabular}{|c|c|c|c|c|}
\hline $\begin{array}{l}\text { Scored } \\
(+ \text { or }-)\end{array}$ & \multicolumn{4}{|c|}{ Question } \\
\hline $\begin{array}{c}\text { Full } \\
(f)\end{array}$ & \multicolumn{4}{|c|}{$\begin{array}{l}\text { I currently have an equivalent amount of responsibility as my master teacher } \\
\text { when considering the responsibilities of the teaching profession. }\end{array}$} \\
\hline+ & $\begin{array}{c}1 \text {-stronglydisagree } \\
-2\end{array}$ & $\begin{array}{l}\text { 2-disagree } \\
-1\end{array}$ & $\begin{array}{l}3 \text {-agree } \\
+1\end{array}$ & $\begin{array}{l}\text { 4- strongly agree } \\
+2\end{array}$ \\
\hline Peripheral & \multicolumn{4}{|c|}{$\begin{array}{l}\text { I currently have less responsibility than my master teacher when considering } \\
\text { the responsibilities of the teaching profession. }\end{array}$} \\
\hline (p) & 11-stronglydisagree & 2-disagree & 3 -agree & 4- strongly agree \\
\hline - & \multicolumn{4}{|c|}{$\begin{array}{l}\text { My responsibilities for teaching and learning currently require and } \\
\text { equivalent amount of time as the responsibilities of my master teacher. }\end{array}$} \\
\hline $\begin{array}{c}\text { Full } \\
(f)\end{array}$ & $\begin{array}{c}1 \text {-stronglydisagree } \\
-2\end{array}$ & $\begin{array}{c}\text { 2-disagree } \\
-1\end{array}$ & $\begin{array}{l}3 \text {-agree } \\
+1\end{array}$ & $\begin{array}{l}\text { 4- strongly agree } \\
+2\end{array}$ \\
\hline+ & \multicolumn{4}{|c|}{$\begin{array}{l}\text { My responsibilities for teaching and learning currently require less time than } \\
\text { my master teacher. }\end{array}$} \\
\hline $\begin{array}{c}\text { Peripheral } \\
\text { (p) } \\
-\end{array}$ & -2 & -1 & +1 & +2 \\
\hline
\end{tabular}

Twenty-four of the 29 interns completed the questionnaire. Scores ranged from eight to 45 . The researcher selected the five lowest and five highest scoring interns to solicit participation in the study. Two of the five lowest scoring interns declined participation. The lowest scoring participants were considered the most peripheral in the study and were referred to as the peripheral group. The five highest scoring participants were considered closest to full participants in the community of practice and were referred to as full participants throughout the study. Figure 3 provides a visual representation of the participant selection process. 


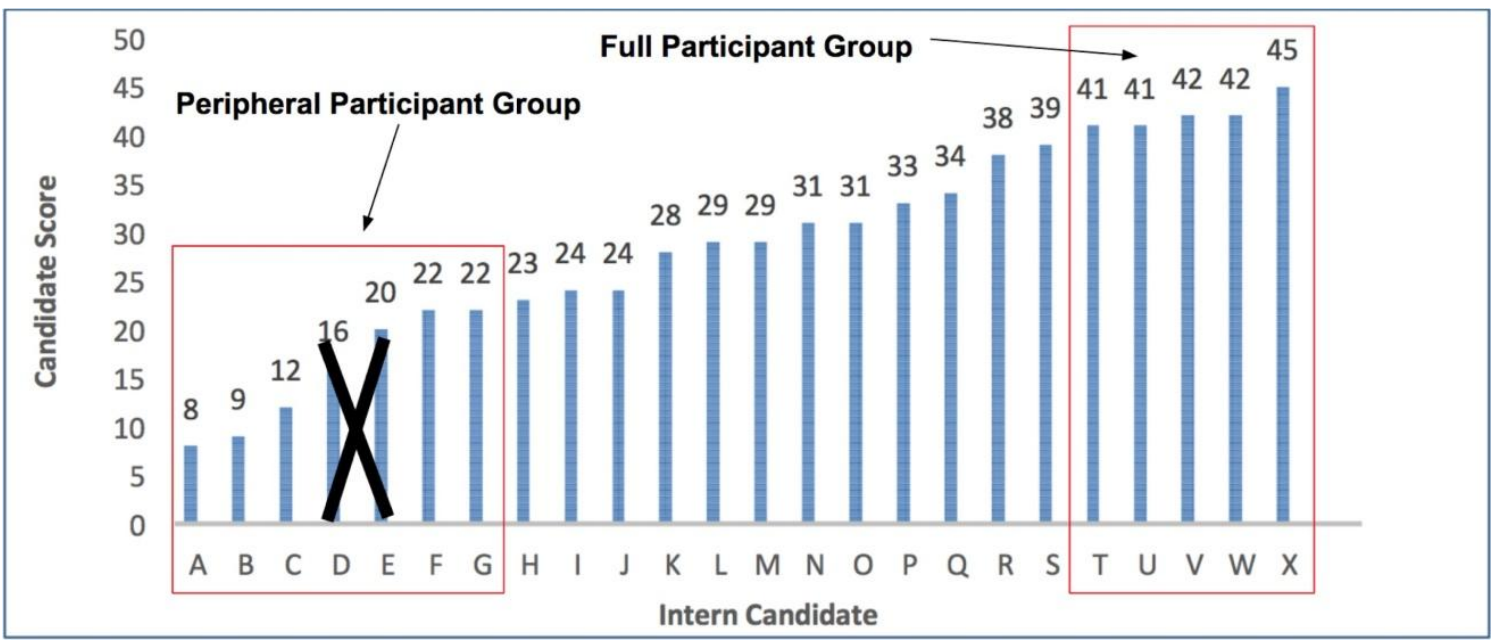

Figure 1. Intern response scores from participant selection questionnaire. Bars represent total score accumulated by study candidates relative to degree of socialization into community of practice. $\mathrm{X}$-axis represents 24 respondents, and Y-axis represents scores reported by researcher.

\section{Setting}

In order for the researcher to gain insight into the defined research questions, a setting with an immersive clinical experience was necessary. A new internship program at the southwest Missouri university provided a relevant, bounded setting and context for gathering data appropriate for answering the research questions. The bounded nature of the internship program also provided an isolated context, allowing the researcher to identify specific socialization facets that may or may not have impacted self-efficacy development experiences. As Yin (2003) stated, "you would use the case study method because you deliberately wanted to cover contextual conditions-believing that they might be highly pertinent to your phenomenon of study" (p. 13).

\section{Data Collection}

The researcher contacted master teacher participants via e-mail for focus group interviews. Participation was based on serving as a master teacher to one of the selected interns. The researcher received 100\% consent to participate from selected master teacher participants. Once consent was obtained, the researcher provided date and time information for focus group interviews, and the outside data collector facilitated the remainder of the data collection and communication process.

The researcher utilized triangulation, member checking, and peer debriefing in order to ensure trustworthiness with the qualitative data. The researcher triangulated data from three sources in order to obtain data relevant to the research questions. Journal data were gathered from interns via journaling questions, focus group interviews were conducted with peripheral and full participant interns, and focus group interviews were conducted with the respective master teachers of peripheral and full participant interns.

\section{Data Analysis}

The researcher analyzed the fully anonymous journal and interview data using Creswell's (2003) provided five steps for qualitative analysis. At the conclusion of the initial analysis reading, the researcher began to consider what ideas had been repeated, and what themes were present in relation to predetermined themes that guided journal and interview questions.

The researcher conducted a second analysis reading of the data in which the coding process was begun. The researcher designed study questions to elicit information in the area of eight predetermined themes. Four themes were generated for Bandura's (1977) social learning theory of self-efficacy and four from Lave and Wenger's (1992) theory of legitimate peripheral participation. Predetermined themes and their corresponding theory can be found in Table 2. 
Table 2 Themes Predetermined by Researcher and Corresponding Theories

\begin{tabular}{ll}
\hline Theorist/Theory & Theme \\
\hline Bandura (1977) & Mastery Experiences \\
Self-efficacy theory & Vicarious Experiences \\
& Verbal Persuasion \\
& Physiological and Emotional States \\
& \\
Lave and Wenger (1992) & $\begin{array}{l}\text { Responsibility Comparison } \\
\text { Legitimate peripheral participation theory } \\
\end{array}$ \\
& $\begin{array}{l}\text { Identity in Community of Practice } \\
\text { Language and Jargon Acquisition } \\
\text { AccessComparison }\end{array}$ \\
\hline
\end{tabular}

Tables 3 and 4 provide the number of times themes recurred during analysis.

Table 3 Number of Times Themes Recurred in Participant Interview and Journal Responses

\begin{tabular}{ll}
\hline Subtheme & Number of Recurrences in \\
& Response Data \\
Mastery Experiences & 65 \\
Vicarious Experiences & 46 \\
Verbal Persuasion Experiences & 50 \\
Physiological and Emotional State Experiences & 42
\end{tabular}

Table 4. Number of Times Themes Recurred in Participant Interview and Journal Responses

\begin{tabular}{ll}
\hline Subtheme & Recurrences in Response \\
Data & \\
\hline Responsibility Comparson
\end{tabular}

Responsibility Comparison

Intern Identity in Community of Practice

Language and Jargon Acquisition

Access Comparison
68

24

32

Note. Numbers represent recurrences of subthemes in responses.

\section{Analysis of Research Question 1}

The researcher coded mastery experiences as any time a success or failure within the classroom or larger community of practice was mentioned. An example of a failure noted by a participant is, "Today I realized I had failed at persevering with a student who had been consistently displaying disrespectful behavior." Another intern stated, "Something I have succeeded at in the classroom is building relationship with students." This type of statement recurred often in the data. Within the mastery experience theme, the researcher identified four recurring subthemes in participant responses, which are described below.

Mastery experiences contributed to meaningful learning and growth: Interns and master teachers saw failing and succeeding with obstacles as highly valuable experience that was difficult to attain in any other manner. "I was given the time to persevere and struggle with my own inadequacies and I learned what works best for me." aster Teacher statements reiterated this sentiment, "I would say through failure she became successful." Another master teacher stated, "I think just giving them the opportunities and letting them fail, and then giving them that feedback and talking through things was very effective." Interns and master teachers provided numerous examples communicating the value of learning through their successes and failures.

Peripheral Interns focused on successes and failures with student and parent management: Peripheral Interns specifically communicated examples of struggles with whole class management and individual student management. "I realized that I had failed at persevering with a student who has been consistently displaying disrespectful behavior." This type of statement was common throughout peripheral responses, communicating a specific focus on struggles and successes with the management of students. 
Two intern responses discussed failures with parent communication and relationship management. Interns communicated making mistakes with parent communication and management that resulted in the need to work with their master teachers to communicate the failure and reach a solution.

Interns focused on successes and failures with curriculum and pedagogy: Intern and master teacher participants provided multiple responses detailing successes and failures with curriculum and pedagogy. "I thought it was going to be the best lesson ever... It ended up being the biggest headache... It was just awful." One intern shared a similar experience with an attempted paraphrasing lesson: "They were just copying and pasting... It just shows lack of experience... it really taught me a lot about preparedness and just thinking every little thing through." Interns noted that with each failure and/or success related to curriculum and pedagogical practices, they learned and were able to shift their understanding and future practice.

Peripheral master teachers noted being afraid of allowing interns to fail: The researcher found one final subtheme to emerge in the response data of peripheral intern and master teacher responses. Master teachers shared their struggles with allowing someone else to have control in their classroom and the difficulty in allowing their intern to fail when they were there to help prevent the failure. "I think one of the things I struggled with as a new mentor teacher for the last couple of years was allowing our interns to fail." Another peripheral Master teacher stated, "It's hard, I'm a control freak... whenever my intern would take over, and I saw the class management, I wanted to step in and fix them so they would pay attention." Intern responses within the peripheral interview data reiterated this subtheme.

Vicarious Experiences: The researcher coded various experiences throughout analysis of data that were deemed vicarious experiences. An example of this recurrence was represented in the statement "Today I was able to watch my master teacher teach different lessons to the class, and complete duties of an educator including attending a meeting for a student who has anxiety, anger, and other various emotional disorders." Additionally, a master teacher response representative of this theme is "She saw me make a whole lot of mistakes throughout the day, so when she made one, she was like oh, okay, that's just normal." Within the mastery experience theme, the researcher identified two recurring subthemes in participant responses.

Interns focused on the inherent value of observing teaching and learning: The researcher identified many responses within vicarious experience data that attributed observation-based experiences to learning and growth. One intern shared the value of observing their master teacher engaged in facilitating lessons:

I observed my master teacher daily. His mini lessons run so smooth... students stay engaged the whole time... I took many mental notes of how to begin a mini lesson, how to keep it flowing smoothly, how to get students to work with an activity in a timely manner, and how to conclude the lesson. In addition, interns reported vicarious experiences related to teaching, learning, and student management as valuable, because they provided a means to gage their own practices. "These experiences have given me a baseline to follow."

Full interns valued observation of nonteaching tasks and duties: While learning and growth were regularly attributed to the observation of teaching, learning, and student management, full participants repeatedly identified the observation of nonteaching- related tasks and duties as an opportunity for learning and growth. Example tasks included attending 504 meetings, IEP meetings, staff meetings, and managing before- and after-school duties. full participants seemed to place a high value on these experiences.

I would not have been experienced, going to these meetings, and knowing about his 504 plans, and different things like that... I've seen the progression... we got to see like setting up classrooms and all of the time and effort that goes into that. Full master teachers spent ample time touting the value of observing nonteaching experiences during the internship. Another intern expressed the value of understanding what teaching requires beyond the classroom:

There are so many things, of tasks that you have to do in a given day. Watching and observing. That is the biggest value there is, understanding how the structure of your day happens. Or who you have to talk to. Or what responsibilities that you have, or you have put upon yourself.

These ideas were regularly represented throughout data in full responses and their master teachers.

Feedback and coaching: During analysis, the researcher identified recurrences referencing instances of verbal feedback and coaching. "During a social studies lesson today, my master teacher provided me with a great suggestion during reflection time post-lesson," communicated an example of this type of experience. Another example was "I talked before about feedback from my master teacher, just always getting negative feedback, or no feedback at all." Four subthemes were identified in the area of verbal feedback and coaching. 
Peripheral master teachers did not provide sufficient feedback to their interns: Responses of peripheral participants and their master teachers related to verbal persuasion provided evidence that master teachers did not provide sufficient and/or effective verbal feedback. "I talked before about getting feedback from my master teacher, just always getting negative feedback or not feedback at all" and "I would have loved to have had more feedback." This subtheme was consistently reiterated, "I think I would have benefited from more verbal feedback." Additionally, master teachers also noted uncertainty with how to provide effective feedback. "I don't think she knew she was struggling, and I didn't really know how to approach it, because I think she thought at that time she was doing okay," indicating a lack of understanding with providing feedback.

Full interns and master teachers experienced relationship issues: The researcher also identified evidence of relationship struggles between peripheral interns and their master teachers mentioned during verbal persuasion experiences in responses. "Sometimes if you don't have that good relationship... what you feel like is a success turns into a failure because you're not being validated," Another intern shared, "We just don't get each other and don't understand. Any feedback that's ever had, she just doesn't ever give me good feedback." Master teachers' responses echoed these concerns. Master teachers mentioned multiple times relationship barriers with their Intern were obstacles to providing effective feedback and coaching.

Feedback and coaching were valuable to the learning and growth of interns: A dominant subtheme that was present in the responses on peripheral and full interns and their master teachers was that of learning and growth attributed to verbal feedback.

Participant responses consistently communicated feedback and coaching created opportunities for interns to reflect on experiences and make adjustments to practice. "Feedback has been a key asset in my growth of my teaching skills and has built confidence in my teaching," was representative of many statements in the data.

Full master teachers provided constant and/or consistent feedback to their interns: The researcher's analysis of full participant responses revealed a final subtheme rarely present in peripheral responses. Nearly all full interns reported that their master teacher provided consistent or constant feedback throughout the internship experiences. "My master teacher is constantly providing me with positive verbal feedback that helps me grow as a teacher," and "The constant feedback has been a key asset in my growth of my teaching skills and has built my confidence in my teaching," represent this finding.

Physiological and emotional states: The final theme noted related to Research Question 1 was representative of intern and master teacher responses communicating the impact of stress on performance. The researcher coded these experiences as physiological and emotional state experiences. One intern example was, "I think the pressure of needing a job has been overwhelming right," another example referencing clinical experience and coursework was, "That was a really hard balancing act, and I think it caused unwanted stress for me and my master teacher. And I know it probably played off into the students and their behavior too." Within the mastery experience theme, the researcher identified three recurring subthemes in participant responses.

Stress resulted in decreased teaching performance by interns: Both peripheral and full participants reported stress during the internship caused a decrease in performance in the classroom and the teaching and learning process. While these instances were present numerous times, multiple Interns noted that stress did not impact their performance negatively, and while heavy at times, was a positive experience. "There were many times I felt my performance was lacking as an Intern due to outside stress," and "Stress affected my patience and grace for students and my teaching ability in the classroom." represent these findings.

University coursework presented a significant stressor for interns: Peripheral and full participants reported university coursework as a significant stressor during the internship experience. Interns and master teachers felt that coursework was a consistent stressor during the internship experience, and at times, coursework's unrelated focus in reference to experiences occurring in the classroom made the work even more troublesome. "Trying to finish coursework while teaching lessons throughout the day and acting as a substitute was extremely stressful." Master teachers shared in these feelings about stress causing experiences in similar responses. "My intern was a lot more stressed about the tasks that they were assigned than the actual teaching."

Stress resulted in learning and growth for interns: The researcher found that all self-efficacy source experience themes contained the subtheme of learning and growth. peripheral and full participants and their master teachers valued stress in the classroom, despite the discomfort, and at times, lack of performance that it produced. Participants touted the value of stress in its preparation of interns for the first year of their teaching career.

Analysis of Research Question 2 
Research Question 2 asked, "What differences, if any, exist between self-efficacy source experiences of peripheral participants and full participants in a community of practice?"

The researcher analyzed open-ended questions in the form of intern journal questions and intern and master teacher focus group interviews. From the researcher's analysis of journal and interview responses related to Research Question 1 , the four themes within the data related to efficacy source experiences were analyzed for notable differences. Each of the notable differences identified by the researcher were then described in detail by the researcher within the theme category. No differences were found between the physiological and emotional state responses of full and peripheral participants.

Mastery experience differences: In analysis of peripheral and full responses within the mastery experience theme, the researcher identified a notable difference in the types of successes and failures that were communicated by participants. While both full and peripheral participants specifically identified failures and success related to classroom and parent management and pedagogical successes, there were distinct differences in the number of times the different experiences were mentioned. Within the peripheral, management-related issues were mentioned 26 times. Within the full, management-related issues were mentioned three times. Management issues were defined as any time participants noted struggling with the management of student behavior, teaching tasks, and/or parent communication. Additionally, the tendency of full participants to focus on pedagogical-related experiences over management-specific ones was also a defining characteristic. Full participants made mention of pedagogy specific 10 times as opposed to three mentions of management issues. Peripheral participants mentioned pedagogical successes and failures seven times while mentioning management related experiences 26 times.

Notable differences were found between the types of experiences that Peripheral and full interns made mention of as growth creating opportunities. Both groups mentioned a variety of learning and growth moments. Peripheral participants demonstrated a slightly greater diversity in the types of learning accomplished. Full participants tended to focus the majority of their moments on pedagogical issues while peripheral participants leaned toward management and parent interaction. No distinct differences separated the learning and growth statements made by the two groups. The groups clearly noted failures as creating opportunity for growth. Reflecting on failure was touted to be a strong element of growth. An area to take note of is the perception of failure by the interns and master teachers. Within the peripheral master teachers, failure was mentioned three times as a difficult facet to allow.

Vicarious experience differences: Analysis of peripheral and full responses with the vicarious experience theme revealed a notable difference in the types of observation- based experiences that were attributed to learning and growth during the internship. Both peripheral interns, full interns, and their respective master teachers made similar mentions of observation-based experiences in their responses. Both peripheral and full participants made multiple mentions of teaching, learning, and classroom management- based observations that were valuable to their growth. There was a variance in the number of mentions, with peripheral participants making mention of these experiences 20 times in comparison to nine mentions by full participants. A defining difference between the vicarious experiences of the two groups was the mentioned value of nonteaching- related observation experiences. Full participants noted 13 times the value of observational experiences related to nonteaching tasks and duties. These statements included observation of tasks such as 504 meetings, IEP meetings, parent communication, and orientation nights. From the peripheral, nonteaching observations were only mentioned onetime.

Verbal persuasion differences: Analysis of peripheral and full participant responses with the verbal persuasion theme revealed significant differences in the amount of feedback that was received by peripheral and full participants as well as the quality of relationships held between interns and their master teachers. The researcher found a notable difference in the responses of peripheral and full participants and their respective master teachers within the subthemes related to the amount of feedback given and received during the intern experience. Four of five peripheral interns reported a lack of sufficient feedback from their master teachers. In addition, peripheral master teachers reported struggling to provide effective feedback. In contrast, no full interns or their master teachers reported a lack of feedback or difficulty providing or receiving feedback. Four of five full participants did, however, note that they were provided with constant or consistent feedback. The researcher also noted that despite the reports of lacking feedback within the full, one did report receiving sufficient feedback from her master teacher in her journaling response.

In addition to the noted difference in feedback quantity between peripheral and full participants and their master teachers, an additional area of contrast was found between the verbal persuasion experiences of full intern participants and peripheral participants. Three of five peripheral intern participants reported that relationship issues between themselves and their master teachers contributed to struggles with feedback and communication between themselves and their Master Teacher. No full interns or their master teachers reported any issues with the relationships between interns and master teachers. 


\section{Analysis of Research Question 3}

Research question 3 asked, what legitimate peripheral participation theory facets of the clinical experience affected the process of socialization from peripheral participant to full participant? Listed below are the themes identified, such as responsibility comparison, responsibility levels, identity, relationships being accepted into the community of practice.

Responsibility comparison. During the theme identification process, the researcher identified the responsibility comparison theme as experiences noted in which the intern or master teacher made a comparison of their level of responsibility. "I truly feel that I had an equal level of responsibility to my master teacher," is representative of a comparison statement. Additionally, the researcher also included instances of inherent lack of responsibility in which the intern or master teacher may not have made a direct comparison, but the responsibility difference was present in the statement. "The kids are a lot of my master teacher's responsibility. I've tried to show my authority in the class, but at the end of the day the kids know that my master teacher is really the one who's calling the shots." Lave and Wenger (1992) presented the level of responsibility held by members within a community of practice as a defining characteristic when considering one's degree of socialization. Within the responsibility comparison theme, the researcher identified three recurring subthemes in participant responses.

Responsibility levels were generally less for peripheral interns than full interns. The researcher found that varying degrees of responsibility were present between group responses and individuals within groups. The researcher noted 34 times which responsibility comparisons were made between intern and master teachers. Within responsibility comparison responses, instances of equivalent responsibility between master teacher and intern and instances of less responsibility with intern than master teacher were noted. Peripheral participants made five mentions of having equal responsibility to their master teacher, but all five interns reported at other times that they had less responsibility than their master teacher and often multiple times. Similar findings existed in full response, but peripheral participants overwhelmingly made referred to having less responsibility than their master teachers when compared to full participant responses.

The researcher found that responses for most interns varied at different points during journal and interview responses. One intern reported similar responsibility to their master teacher within the classroom and school community, and even greater degrees of responsibility at times, but later reported lacking some responsibility with parent e-mail. Several interns reported having equal responsibility, but made statements recognizing that the ultimate control of the classroom was in the hands of the master teacher: "It's that teacher's classroom. Her name is on the report card. I don't think there's ever a time where you're like, this is my classroom, because it's not." When discussing who had more responsibility, another intern added, "Probably more her. It's her classroom," which echoed the idea communicated that regardless of responsibility, the classroom was ultimately the responsibility of the master teacher.

A notable variance that the researcher identified within the responsibility level variances were perspectives of master teachers of peripheral an full. Four of five master teachers of full interns identified their intern as being equally responsible as themselves within the community of practice. They intentionally allocated equal responsibility to their intern. No peripheral master teachers reported this. Conversely, two peripheral master teachers reported their intern having less responsibility while no full master teachers reported this. Master teachers of peripheral participants generally saw themselves as holding more responsibility for the tasks within the school than their interns. Full master teachers had a greater tendency to identify themselves as equals to their interns and distribute responsibility as such. One shared how they withheld responsibility from the intern, creating a variance in responsibility:

She felt like we were completely co-teaching all the time. But then the parent piece, that was my piece. I would let her read all the parent communication, and if she wanted to send something home, I was totally fine with that. But with See Saw, I shared it with my principal, so without giving her my login she couldn't be on the See Saw, but she could see mine, or she could be on it as a student. Similarly, another shared that while their intern likely saw themselves as equally responsible, they were not: "I don't think she knows... There was a lot of things that I was doing behind the scenes." full master teachers made contrasting remarks that revealed a greater degree of responsibility equality both in reality and perception:

My intern's responsibilities were my responsibilities. Whatever duties I had, she did them along with me. Whatever clubs, or afterschool activities that I had, she did them as well. It was equal. It was not anything different than I didn't expect of myself to do. She did them too and she did them with ... Never complained about it, or at least never said anything to me. Full master teachers consistently confirmed this statement. They saw their intern as an equal in reference to responsibility and acted accordingly. Full interns reported increasing levels of responsibility over time. Though the researcher found varying degrees of responsibility to be present within both peripheral and full responses, interns within the full regularly reported an evolution of responsibility over time within the internship. Evolution of responsibility was found eight times in full responses. 
This subtheme was only present once in peripheral participant responses. Full interns reported that their master teachers structured their responsibility within the classroom and community of practice to increase over time. Their responsibility moved from lower levels in the beginning to an equal level of responsibility later in the internship. One full participant intern reported, "Toward the beginning of the year, my master teacher definitely had more responsibility because she was responsible for leading all subjects... as the year went on, I began taking over subjects a little at a time."

Another reiterated this evolution of responsibility: "I was the same way, starting slow, and then gradually taking over more." Interns reporting evolution of responsibility all shared that they were near equals to their master teacher during the latter parts of the internship experience. Additionally, some did report their master teacher's gradual assumption of control as the internship experience drew to a close.

Identity. Lave and Wenger (1992) also presented identity within a community of practice as a characteristic relevant to socialization. The researcher identified numerous instances in which interns and/or their master teachers provided responses discussing identity-related issues. The researcher included statements in which interns directly discussed their identity related to the culture, or the way business is conducted within the community of practice, such as, "I always feel welcome and that I am a full participant in the culture of our school. Whether it is spirit days, staff meetings, or events for school, I have always been included in everything." In addition to this type of statement, the researcher also included indirect statements related to identity issues such as acceptance by community of practice members. "In faculty meetings, literacy meetings, quarterly math meetings, I still feel like I don't want to overstep my boundaries because it's not really my place yet." Within the identity theme, the researcher identified five recurring subthemes in participant responses.

Peripheral interns struggled with relationships and being accepted into the community of practice. In analysis of response data, the researcher identified a notable subtheme that only existed in the responses of peripheral Interns and their master teachers. Peripheral interns and their master teachers reported 11 times that relationships were an issue for the Intern in the community of practice or that they were not fully participating members. Full interns and their master teachers had no reports of this subtheme. Relationship issues between the intern and the master teacher were reported, as well as between the intern and other community of practice members.

When considering their identity within the community of practice, one peripheral intern shared that even at the conclusion of the internship experiences, she still did not feel comfortable with some members of the community of practice: "I still feel like there are teachers that I can't call by their first name... maybe it's just the way they act, or how they present themselves..." Another peripheral intern provided further examples of their inability to fit into the community of practice and converse with everyone: "It's just like here's your room, here's your grade level, don't mix. I don't feel like I know the specialist teachers. I don't know the SPED teacher. I see my principal, and she's really nice... but I don't know her."

As interns reported an inability to become a fully functioning member of the community of practice, master teachers provided multiple responses communicating that their interns did not fit into the building's culture or community of practice: "I don't think mine changed. I don't think she fit the building." When asked to consider whether or not her intern was a member of the culture of the building, a peripheral master teacher replied with a prompt "no." Another reported a similar experience with her intern, noting that they were an integral part of the classroom, but not of the entire community of practice. The researcher found the overarching theme throughout the majority of peripheral participant responses that generally, peripheral interns did not fully reach the point of identifying themselves as full members of the community of practice, even at the conclusion of an immersive yearlong experience. This statement offers a relevant summary of the subtheme: "I still don't feel like it's my place to step in. In faculty meetings, literacy meetings, quarterly math meetings, I still feel like I don't want to overstep my boundaries, because it's not really my place yet."

Full interns became fully participating members of the community of practice.

In contrast to findings of relationship issues and lack of identity within the community of practice, the researcher identified numerous statements in which interns and master teachers identified interns as fully participating members of the community of practice. While the subtheme was present in both peripheral and full responses as well as their master teachers, five responses were present within the peripheral data and 18 within full data. All full interns made multiple mentions of being a fully participating member of the community of practice while only two peripheral interns provided similar responses.

Full interns felt as though they were equals in their communities of practice.

Interns were welcomed early on and became fully participating members with the progression of time. Interns reported being friends with community of practice members and being seen as a peer to other members. 
They felt included in everything that happened within the community of practice including events that went beyond the normal school day; "I made a lot of long-lasting relationships there. I feel like it's my home away from home because I'm there all the time." Others reported that their school had become their family; "My team feels like my family at this point... As far as being a teacher, I feel like one of them." Master teachers of full intern participants solidified this subtheme in their responses demonstrating agreement with Intern identity in the community of practice. Additionally, four full participants were reported as being hired into their community of practice building and/or district by either themselves or their master teacher. It was also noted by the researcher that two members of the group reported being fully participating members of the community of practice. Though two peripheral interns made these statements, one also mentioned relationship issues and feeling comfortable with all members of the community and asserting themselves in previous interview responses.

Fully identifying interns received early acceptance into the community of practice. Analysis of subtheme statements revealing full membership identity within the community of practice revealed an additional recurring subtheme. All Interns of peripheral and fulls reporting full participation within the community of practice also mentioned early acceptance and a welcoming community in the beginning stages of the internship. No reports of this subtheme were made by Interns who had relationship issues or did not identify as full participating members of the community of practice.

Examples of the welcoming environment and early membership can be found in the following intern and master teacher responses.

I feel like at my school, we were always... there are interview at the very first staff meeting, Like, they are one of us, they are going to be here all year, and they were super welcoming, And it's never really changed from that, If anything, it's just gotten better. (FIC)

I think from the very beginning at our building, they were considered part of our team in everything that we did. They were invited. It wasn't like, "Okay, interns go sit over there. We're sitting over here." They were just all meshed together and made to feel like they were part of the staff. I had that mentality as well" (FMB)

The researcher found that communities of practice welcoming interns early in their experience resulted in interns who identified themselves as fully participating members of the community during the latter part of the experience in which they were interviewed.

Identity within the community of practice evolved over time. The researcher found a final subtheme present in the discussion of identity with the community of practice by interns and their master teachers. The subtheme was present in peripheral and full responses and their master teachers, though predominantly identified in full responses.

Participants reported that their identity within the community of practice evolved over time. Interns moved from the periphery of the community of practice to being a more fully participating member as more time was spent in the internship and the community of practice. A full intern attributed her identity within the community of practice to the extended length of time in the internship; "Because I student taught at my school for a year, I was looked at the same way teachers were looked at and not just like a student teacher." Another shared how being in the community of practice for an extended time helped interns to identify themselves differently within the community:

I was always approached to see if I had any new ideas for something...I just can remember it forced you to find your voice within the school, even though they say you are part of the team. It takes time to really feel that way.

The researcher found that the attribution of time to increased and improved identity within the community of practice was a regular occurrence. Master teachers agreed and provided responses in the support of time as a factor in identity evolution as well.

Language and jargon. Interns and master teachers made several mentions related to the unique academic language and jargon experienced during their internship. Lave and Wenger (1992) provided that the acquisition of the unique language within a community of practice is another defining characteristic of socialization. The researcher identified these experiences as the language and jargon acquisition theme.

Evolution of understanding with the language and jargon is represented by the following statement, "At first I was not able to understand educational jargon." Lack of acquisition was inherent in statements such as, "I experienced a lot of terminology that I was not at all familiar with." Within the language and jargon acquisition theme, the researcher identified one recurring subtheme in participant responses.

Intern understanding of language and jargon evolved over time. Experience related to the understanding and acquisition of educational language and jargon recurred in responses of both peripheral and full interns. Thirteen responses were relevant to this theme, with seven responses from peripheral participants and six from full participants. The researcher found no distinct variances between responses. 
Interns and master teachers reported that interns acquired the unique language and jargon used in the educational community over time. Interns reported that time was of value during his experience and helped them to acquire and use the unique language of the community of practice, as well as be prepared for the use of the language in their future careers: "I have experienced academic language and educational jargon from day one. At the beginning of the year all the educational language and jargon was all new for me and being able to understand what it all meant took time." Another reported, "As the school year continued, I was better able to not only understand the academic language and jargon, but use it effectively in conversations." Interns overwhelmingly identified that language acquisition was a result of time and immersion.

Access comparison. The researcher noted a fourth and final theme in the analysis of data related to Research Question 3. Numerous intern and master teacher responses discussed intern access to people, places, and resources within the school setting. Lave and Wenger (1992) provided that access to these facets is key to the socialization of any individual into a community of practice. Participant responses included statements related predominantly to building and resource access. "They had everything that we have really, besides access to the building." Within the language and jargon acquisition theme, the researcher identified three recurring subthemes in participant responses.

Interns generally had equivalent access to their master teachers. The researcher identified that access to people, places, and resources was generally a non-issue for peripheral and full participants. Participants made ten mentions of equal access to people, places, and resources, with five mentions from peripheral interns and their master teachers and five from full participants and their master teachers. Interns generally agreed that they were given sufficient access to anything they would need for teaching and learning in the classroom and function within the school setting: "I definitely had access to all the resources, people, and locations that my master teacher did." Master teachers shared that they attempted to make every necessary resource for teaching and learning available to their intern: "She could use anything that's in my room, and she was comfortable to get in my desk, the closet, all the books on the shelf."

Interns lacked building access. The researcher identified that lack of building access was a regularly mentioned issue regarding access to people, places, and resources. peripheral and full interns and their master teachers described the inability to access the building in the mornings as a burden and barrier. Interns described frustration with the inability to access the building in the mornings in order to prepare for the day. They were left to knock on windows and doors if they wanted to arrive and work before students entered the building.

One of the main things that I really dislike about my experience is that we don't have a way to get into the building without a teacher opening the door for us... If we want to get there before 7:00 we have to sit out in the cold, standing by the door until another teacher will come and let us through the door.

This frustration was found in the majority of participant responses. Interns and Master teachers were also frustrated by the barrier that lack of building access presented when interns were facilitating student activities beyond the school walls such as recess, "When I take the kids to recess duty, that's kind of a pain sometimes." Master teachers and interns would have preferred intern access to the building.

Full interns lacked credentials to technology-based accounts. Full interns mentioned frustration with their lack of access to technology accounts and district WIFI. Interns felt that it was burdensome for them to have to request their master teacher's credentials for online and digital resources: "They have access to different accounts, websites, profiles that us student teachers did not have access to. Though it was easily fixed with the sharing of account information, it still made it difficult sometimes when researching or preparing lessons." Other interns mentioned frustrations with the inability to access accounts such as Discovery Education without shared credentials. One shared that this inconvenience resulted in not using the resources during instruction. It was apparent that all accounts were accessible upon request of credentials from the master teacher, but the inconvenience was burdensome.

\section{Conclusions and Recommendations}

Conclusions for research questions 1 and 2. The following conclusions serve to illuminate understanding of Research Questions 1 and 2. Research question 1 addressed if socialization into a community of practice impacted self-efficacy source experiences. Question 2 sought to identify differences, if any, between self-efficacy source experiences of peripheral participants and full participants in a community of practice. The researcher found distinct differences between response characteristics of the intern and master teacher groups as defined by their differing levels of socialization.

Responses provided evidence of variance in efficacy source experiences corresponding to varying degrees of socialization, as well as evidence of differing experiences with socialization facets as defined by Lave and Wenger (1992), which often corresponded to intern participant degrees of socialization as well. 
Efficacy source experiences created valuable learning and growth opportunities for preservice teachers. Intern participants and their master teachers regularly reported the value of efficacy source experiences as defined by Bandura (1997). Every intern and master teacher participant reported efficacy source experiences as being important to the learning and growth of preservice teachers during clinical experience. This finding indicates that value exists in tailoring clinical experiences to incorporate efficacy source experiences. Intentionally engaging preservice teachers in efficacy source experiences is likely to leverage greater degrees of learning and growth as they prepare to enter the teaching profession.

Socialization appears to be connected to efficacy source experiences of preservice teachers. The researcher found participant responses varied by groups organized by varying degrees of socialization into the community of practice. Experiences held by peripheral interns, as defined by their lesser degree of socialization and their corresponding master teachers, were different than experiences reported by full interns, as defined by their greater degree of socialization and their corresponding master teachers. The quality of self-efficacy source experiences is a key element in the development of self-efficacy beliefs as reported by Bandura (1997). Varying degrees of experiences can both positively and negatively impact self-efficacy beliefs. Bandura suggested that negative source experiences could often result in declining self-efficacy beliefs in contrast to leveraging greater self-efficacy beliefs through positive source experiences. Socialization appears to be connected to the amount of feedback a preservice teacher receives from their mentor. Interns reporting a lesser degree of socialization regularly reported a lack of feedback from their master teacher. Interns reporting greater degrees of socialization did not report similar experiences. The level of socialization of of interns is linked to the amount of feedback received by their master teacher or mentor. Noting the significance of verbal persuasion on self-efficacy development drawn in this study's conclusions and previous studies (Filatov \& Pill, 2015; Gaffney et al., 2013), recognizing this feedback deficit is critical. Filatov and Pill (2015) identified feedback during student teaching having a direct impact on the self-efficacy beliefs of student teachers. Student teachers receiving greater levels of feedback from their mentors reported higher levels of self-efficacy.

Socialization appears to be connected to preservice teacher/mentor relationships. Of the five intern and master teacher pairs categorized by interns having a lesser degree of socialization, three reported experiencing relationship issues during the internship experiences. Interns and master teachers discussed difficulty with understanding each other and making connections in their relationships. Interns and master teachers of the more socialized group made no such reports of relationship issues.

Research question 3. The researcher drew the following conclusions for research question 3, which sought to identify legitimate peripheral participation theory facets of the clinical experience that affected the process of socialization from peripheral participant to full participant.

Legitimate peripheral participation facets appear to be connected to varying degrees of preservice teacher socialization. The researcher identified two facets of the theory in which variances existed between peripheral and full interns and their master teachers. Facet differences present were related to intern responsibility levels within the community of practice and intern ability to integrate or identify with the community of practice. Lave and Wenger (1992) suggested that membership within a community of practice can be measured by responsibility, identity relevant to culture, access, and the acquisition of the unique language of the community of practice.

Mentor perception and allocation of responsibility affected socialization of preservice teachers. Peripheral interns were not viewed as having the same level of responsibility as their master teachers. Master teachers either intentionally or unintentionally withheld responsibility. Lave and Wenger (1992) contended that a defining characteristic of a fully socialized member of a community of practice is their equal level of responsibility for the happenings within it. It is unknown if intern dispositions or competence affected responsibility distribution, allocation, or perception. Additionally, it is unknown if dispositions or beliefs held by master teachers may have contributed to this conclusion. However, the researcher concluded that withholding of and perception differences in responsibility within the community of practice were a contributing factor to socialization variances between study participants.

Intern acceptance and integration into the community of practice affected socialization of preservice teachers. Lave and Wenger (1992) suggested that acceptance by the community of practice is a linchpin in the legitimization of social learning.

Inherent to acceptance is the ability to establish base-level relationships foundational to necessary interactions facilitating acceptance. Peripheral interns regularly reported adversity when discussing their ability to be accepted into and build relationships with community of practice members including their master teachers.

Near the conclusion of their yearlong internship experience during which time the study was conducted, four of five peripheral interns and three of five master teachers reported this adversity with acceptance. In contrast, neither full interns nor their master teachers made any such reports. 
Acceptance and integration into communities of practice was a contributing facet when considering the degree to which interns socialized. Communities of practice exercise control over socialization facets experienced by preservice teachers. The researcher identified some facets were often reported as being directly controlled by community of practice members within the clinical placement or the community of practice as a whole. Full interns regularly reporting full membership within the community of practice and higher levels of socialization also reported that their community of practice welcomed them as a fully participating member of the community from the beginning. The practice of welcoming newcomers to the community of practice immediately is inherently in the control of none other than the community of practice itself. While strong partnerships between school and university staff may serve to affect this finding, the ultimate control will continue to lie in the hands of the community of practice occupying the clinical placement campus.

Time is an element in the process of socialization of preservice teachers as language acquisition, responsibility, and identity are reported to evolve. Interns and their master teachers regularly reported language acquisition and proficiency evolving over time. They also reported responsibility and identity changing throughout the course of the internship. While Lave and Wenger (1992) never addressed the issue of time, its presence is inherent in their propositions that responsibility and identity evolve as a member moves from peripheral to full participant. Movement and evolution are both contingent on the passing of time. Researchers have yet to agree on the value of time in the clinical experience. Darling-Hammond (2006) suggested that the best teacher preparation programs provided greater lengths of time in clinical experience, while studies conducted by other researchers were far less conclusive and often ambiguous (Hemmerich et al., Henderson, 2015; Hoepner, \& Samelson, 2015; Ross \& Lignugaris- Kraft,2015).

Educational Implications and Recommendations. Designing and sustaining effective teacher preparation programs is a worthy task fraught with ambiguity.

Conclusions drawn from this study should continue to aid in the illumination of the ever- changing best practices of teacher preparation. While rooted in theory that is decades old, the intersection of Bandura's (1997) social learning theory of self-efficacy and Lave and Wenger's (1992) theory of legitimate peripheral participation is worthy of consideration. In today's climate of increasingly demanding preparation standards and a movement toward enhanced clinical experiences, greater understanding to guide changing practice is paramount. The understanding gained from this study holds implications for current practices and suggests direction for future research.

Based on the researcher's conclusions, several implications and recommendations can be made. The researcher identified that learning and growth are a notable result of efficacy source experiences. Woolfolk Hoy (2000) suggested that self-efficacy beliefs of teachers are a leading indicator of teachers' success. Additionally, multiple studies have provided that self-efficacy beliefs are malleable and can be encouraged in programs incorporating the appropriate experiences conducive to efficacy development as well as discouraged with poor experiences (Al-Awidi \& Alghazo, 2012; Aydin \& Boz, 2010; Bautista, 2011; Bergman \& Morphew, 2015; Can, 2015; Dorel et al., 2016; Filatov \& Pill, 2015; Isiksal-Bostan, 2015; Goh \& Matthews, 2011; McDonnough \& Matkins, 2010; Palmer, 2011; Tschannen-Moran \& McMaster, 2010; Tuchman \& Isaacs, 2011; Yoo, 2016). Preparation programs should take note of these findings and consider the degree to which efficacy source experiences are intentionally present in preparation programs. Addressing efficacy beliefs holds potential for increasing teacher effectiveness and decreasing attrition.

In addition to directly designing programs to address efficacy source experiences, preparation programs should also consider the knowledge and training of mentor teachers related to facilitating efficacy source experiences. Though it is unclear as to the root of instances of poor verbal persuasion experiences in the study, lack of feedback is not beneficial to self-efficacy development. Mentor teachers should be fully trained on their roles as a mentor. Preparation programs should consider how mentor teachers are being prepared for the role they are serving.

The researcher concluded that facets of legitimate peripheral participation were directly linked to the level of socialization reported by intern participants. Responsibility, intern identity and acceptance in the community of practice, and access to people, places, and resources are fully controlled by community of practice members. If preparation programs hope to increase effectiveness by enhancing the clinical experience, consideration must be given to the community of practice in which preservice teachers are to be placed. Considerations should move beyond pedagogical practices and assess the community of practice's willingness to accept newcomers, as well as facilitate the best opportunity to allow preservice teachers to fully integrate into their community of practice. As a final recommendation, the researcher suggests that universities consider the amount of time provided for preservice teachers to engage in clinical experience. While the ideal amount of time may not presently be known, preparation programs must place a focus on their desired outcomes and the amount of time required to effectively attain them. 
Movement from a newcomer to the educational community of practice to active member is a multifaceted endeavor. Appropriately designing clinical experiences with time in mind is an important task.

Further Research. Further studies should be conducted to determine the nature of the link between legitimate peripheral participation and self-efficacy source experience differences. Data obtained in the current study did not provide sufficient insight to determine if efficacy source experiences impeded socialization or vice versa. Developing a deeper understanding of this subtlety will offer preparation programs greater insight into effective program design accommodating of self-efficacy development.

In addition, related to the intersection of self-efficacy theory and legitimate peripheral participation theory, the researcher suggests further study be conducted to understand how preservice teacher dispositions and competence affect socialization into a community of practice. Based on the present study, it is unknown as to whether the dispositions of preservice teachers or their competence affected their ability to integrate into the community of practice or be the recipient of greater degrees of responsibility. A better understanding in this area will offer insight to preparation programs seeking to enhance their clinical experiences to facilitate greater degrees of socialization.

Lastly, the researcher suggests that further longitudinal studies be conducted to better understand time's influence on efficacy source experiences as well as socialization. The present study was limited to one moment in time assessed across a range of participants. Studies following individual preservice teachers throughout their clinical experience may offer greater insight into the nature of socialization over time and eliminate external variables such as mentor and preservice teacher dispositional differences. More research in this area will produce understanding further directing preparation program design related to efficacy development and socialization into a community of practice.

\section{References}

Al-Awidi, H. M., \& Alghazo, I. M. (2012). The effect of student teaching experience on preservice elementary teachers' self-efficacy beliefs for technology integration in the UAE. Education Technology Research Development, 60(5), 923-941.

Aydin, S., \& Boz, Y. (2010). Preservice elementary science teachers' science teaching efficacy beliefs and their sources. Elementary Education Online, 9(2), 694-704.

Bandura, A. (1977). Self-efficacy: Toward a unifying theory of behavioral change. Psychological Review, 84(2), 191215.

Bandura, A. (1997). Self-efficacy: The exercise of control. New York, NY: W.H. Freeman and Company.

Bautista, N. U. (2011). Investigating the use of vicarious and mastery experiences in influencing early childhood education majors' self-efficacy beliefs. Journal of Science Teacher Education, 22(4), 333-349.

Bergman, D. J., \& Morphew, J. (2015). Effects of a science content course on elementary preservice teachers' selfefficacy of teaching science. Journal of College Science Teaching, 44(3), 73-81.

Can, H. (2015). Sources of teaching efficacy beliefs in preservice science teachers. Elementary Education Online, 14(1), 333-348.

Creswell, J. (2003) Research design: Qualitative, quantitative, and mixed methods approaches. Thousand Oaks, CA: Sage.

Darling-Hammond, L. (2006). Constructing 21st-century teacher education. Journal of Teacher Education, 57, 300314. Retrieved from http://dx.doi.org/10.1177/0022487105285962

Dorel, T.G., Kearney, S., \& Garza, E. (2016, Winter). Ready from day one? The relationship between length of preserve teacher field residency and teacher efficacy. Critical Questions in Education, 7, 38-52.

Filatov, K., \& Pill, S. (2015). The relationship between university learning experiences and English teaching selfefficacy: Perspectives of five final-year preserve English teachers. Australian Journal of Teacher Education, 40, 33-59.

Gaffney, J. D., Housley Gaffney, A. L., Usher, E. L., \& Mamaril, N. A. (2013). How an active-learning class influences physics self-efficacy in preservice teachers.

American Education Research Conference Proceedings, 1513(1), 134-137. Goh, P. S., \& Matthews, B. (2011). Listening to the concerns of student teachers in Malaysia during teaching practice. Australian Journal of Teacher Education, 36(3), 92-103.

Hemmerich, A. L., Hoepner, J. K., \& Samelson, V. M. (2015, June). Instructional internships: Improving the teaching and learning experience for students, interns, and faculty. Journal of the Scholarship of Teaching and Learning, 15(3), 104- 132.

Isiksal-Bostan, M. (2015). A longitudinal study on mathematics teaching efficacy: Which factors (un)support the development? Eurasia Journal of Mathematics, Science, \& Technology Education, 12,2085-2102. 
Lave, J., \& Wenger, E. (1992). Situated learning: Legitimate peripheral participation. Cambridge, England: Cambridge University Press.

Lin, G.-Y. (2016). Self-efficacy beliefs and their sources in undergraduate computing disciplines: An examination of gender and persistence. Journal of Educational Computing Research, 53(4), 540-561.

McDonnough, J. T., \& Matkins, J. J. (2010). The role of field experience in elementary preservice teachers' selfefficacy and ability to connect research to practice. School Science and Mathematics, 110(1), 13-23.

Palmer, D. (2011, January). Sources of efficacy information in an inservice program for elementary teachers. Science Education, 95(4), 577-600.

Ross, S. W., \& Lignugaris-Kraft, B. (2015, Spring). Multi-tiered systems of support preservice residency: A pilot undergraduate teacher preparation model. Journal of the National Association for Alternative Certification, $10(1), 3-20$.

Smith, M.K. (2009). Jean Lave, Etienne Wenger and communities of practice. The Encyclopedia of Informal Education. Retrieved from http://www.infed.org/biblio/communities_of_practice.htm

Tschannen-Moran, M., \& Hoy, A. W. (2001, February). Teacher efficacy: Capturing an elusive construct. Teaching and Teacher Education, 17(7), 784-805.

Tschannen-Moran, M., \& McMaster, P. (2010). Sources of self-efficacy: Four professional development formats and their relationship to self-efficacy and implementation of a new teaching strategy. The Elementary School Journal, 110(2), 228-245.

Walter, O. (2015). Self-efficacy as an accurate predictor of teaching skills. Journal of Education Research, 9, 310-322.

Woolfolk, A. (2007). Educational psychology (10th ed.). Boston, MA: Pearson.

Woolfolk Hoy, A. (2000, April). Changes in teacher efficacy during the early years of teaching. Paper presented at the American Educational Research Association, New Orleans, LA.

Yin, J. (2003). Case study research: Design and methods (3rd ed.). London, England: Sage.

Yoo, J. H. (2016). The effect of professional development on teacher efficacy and teachers' self-analysis of their efficacy change. Journal of Teacher Education for Sustainability, 18(1), 84-94. 